\title{
Gambaran Deteksi Dini Anemia pada Ibu Hamil di Klinik Helen Tarigan Tahun 2021
}

\author{
Penulis: \\ R.Oktaviance \\ Simorangkir ${ }^{1}$ \\ Aprilita Br.Sitepu ${ }^{2}$ \\ Geniecha Stery Gunny \\ $\mathrm{N}^{3}$
}

Afiliasi :

STIkes Santa Elisabeth,

Medan, Indonesia

Korespondensi:

geniechasterygunny06

@ gmail.com

\begin{abstract}
Abstrak:
Anemia merupakan suatu keadaan dimana sel darah merah atau konsentrasi hemoglobin berkurang sehingga jumlah pengangkutan oksigen tidak cukup atau sel darah merah yang abnormal. Anemia pada kehamilan adalah anemia yang ditandai dengan kadar hemoglobin kurang dari $11 \mathrm{gr} / \mathrm{dl}$ pada trimester kedua. Klasifikasi anemia yaitu, anemia ringan dengan kadar hemoglobin $(8-9,9 \mathrm{~g} / \mathrm{dl})$, anemia sedang $(6-7,9 \mathrm{~g} / \mathrm{dl})$, anemia berat hemoglobin $(<6,0 \mathrm{~g} / \mathrm{dL})$. Deteksi dini merupakan langkah awal untuk pencegahan, dapat dilakukan dengan cara pemeriksaan kadar hemoglobin selama kehamilan.Jenis penelitian adalah deskriptif yang dilakukan di Klinik Helen Tarigan. Populasi semua ibu hamil yang berkunjung di Klinik Helen Tarigan, sampel berjumlah 20 responden. Teknik pengambilan sampel adalah total sampling. Pengumpulan data menggunakan data primer dengan kuesioner. Analisa data dengan menggunakan analisa univariat untuk distribusi frekuensi.Dari hasil penelitian pada pengetahuan tanda dan gejala tentang deteksi dini menunjukkan sebagian besar responden di Klinik Helen Tarigan berpengetahuan cukup (50\%), bila dilihat dari usia menunjukkan sebagian besar ibu hamil dalam usia produktif usia 20-35 tahun (90\%), pendidikan mayoritas SMA (70\%), pekerjaan mayoritas tidak bekerja (75\%), paritas mayoritas multigravida (55\%) dan kadar hemoglobin paling banyak ibu yang mengalami anemia ringan (45\%). Dari penelitian ini, peneliti menyimpulkan bahwa pengetahuan tanda dan gejala tentang deteksi dini anemia di klinik Helen Tarigan adalah kategori cukup sebanyak 10 responden (50\%), dan kadar hemoglobin pada ibu hamil yang mengalami anemia ringan sebanyak 9 responden (45\%), Hal ini dikarenakan kurangnya pengetahuan serta infomasi yang didapatkan ibu hamil tentang deteksi dini anemia.
\end{abstract}

Kata kunci: Kadar hb tentang deteksi dini anemia, Karakteristik, Pengetahuan

\section{Pendahuluan}

Kehamilan suatu kondisi yang dimana seorang wanita di dalam rahimnya terdapat embrio yang berasal dari penyatuan spermatozoa dan ovum dan dilanjutkan dengan nidasi atau implantasi yang diperkirakan sekitar 40 minggu dan tidak melebihi 43 minggu (Plora Novita, 2019). Jumlah ibu hamil di Indonesia pada tahun 2019 tercatat sekitar 5.256.483 jiwa, sedangkan di Sumatera Utara jumlah ibu hamil mencapai 332.810 jiwa (Kemenkes, 2020). Untuk menentukan kehamilan dapat dilakukan dengan mengenali tanda dan gejala, seperti adanya tanda kemungkinan kehamilan, tanda tidak pasti kehamilan. Tanda tidak pasti kehamilan meliputi amenorrhea, mual dan muntah, mastodinia, quickening, sering buang air kecil, konstipasi, perubahan berat badan, perubahan warna kulit perubahan payudara, mengidam, pingsan, lelah dan varices. Sedangkan tanda kemungkinan kehamilan meliputi perubahan pada uterus, tanda pickaceks, suhu basal, perubahan pada serviks, pembesaran abdomen, kontraksi uterus dan pemeriksaan biologis kehamilan dan tanda pasti kehamilan meliputi gerakan janin dalam rahim, terlihat dan teraba gerakan janin, teraba bagian-bagian janin, denyut jantung janin (Dartiwen dan Yati Nurhayati, 2019). 
Penentuan dan dugaan terhadap kehamilan sangat berkaitan dengan pengetahuan tentang fisiologi awal kehamilan. Tanda untuk memastikan bahwa seseorang dikatakan hamil dengan kondisi yang mengindikasikan adanya buah kehamilan atau bayi yang diketahui melalui pemeriksaan dan direkam oleh pemeriksa (misalnya denyut jantung janin, gambaran sonogram janin dan gerakan janin) (Sarwono, 2018). Anemia suatu keadaan dimana sel darah merah atau konsentrasi hemoglobin berkurang sehingga jumlah pengangkutan oksigen tidak cukup atau sel darah merah yang abnormal untuk memenuhi kebutuhan tubuh. Kekurangan zat besi dianggap sebagai penyebab paling umum anemia secara global (Who, 2018). Meskipun ada beberapa hal bisa menyebabkan seseorang yang terdeteksi anemia seperti kekurangan folat, vitamin B12, penyakit kronik, penyakit infeksi dan kelainan bawaan (Aisyah, 2017).

Anemia kehamilan sebagai kadar sel darah merah kurang dari 11 gr atau kurang dari $33 \%$ pada setiap waktu pada kehamilan yang mempertimbangkan hemodilusi yang normal terjadi dalam kehamilan dimana kadar hemoglobin kurang dari 11 gr pada trimester pertama. Anemia pada kehamilan adalah anemia yang ditandai dengan kadar hemoglobin $<11,0 \mathrm{~g} / \mathrm{dl}$ atau $<10,0 \mathrm{~g} / \mathrm{dl}$ pada trimester kedua. Anemia pada kehamilan dibagi menjadi 3 yaitu anemia ringan (hemoglobin 8-9,9 g/dL), anemia sedang (hemoglobin $6,0-7,9 \mathrm{~g} / \mathrm{dL}$ ), dan anemia berat (hemoglobin $<6,0 \mathrm{~g} / \mathrm{dL}$ ). Gejala umum dari anemia adalah kelelahan, sesak napas, nyeri dada, sakit kepala, kulit pucat, ekstramitas dingin, kuku sendok, dan lidah pucat pada pemeriksaan fisik (Anfiksyar et al., 2019).

Adapun penyebab dari kejadian anemia pada ibu hamil karena kurangnya pengetahuan dan pendidikan kesehatan ibu tentang deteksi dini anemia kehamilan dan pendidikan yang rendah.Dengan adanya pendidikan ibu tentang tujuan atau manfaat pemeriksaan kehamilan dapat memotivasinya untuk memeriksakan kehamilan secara rutin, tentang cara pemeliharaan kesehatan dan hidup sehat. Salah satu upaya pencegahan dan penanganan anemia pada ibu hamil diantaranya dengan meningkatkan pengetahuan dan merubah sikap menjadi positif melalui edukasi tentang kebutuhan gizi selama kehamilan, periksa kehamilan minimal 4 kali selama hamil, pemberian zat besi 90 tablet, cek Hb semester I dan III, segera memeriksakan diri jika ada keluahan yang tidak biasa, penyediaan makanan yang sesuai kebutuhan ibu hamil, meningkatkan pengetahuan dan perilaku ibu hamil maupun keluarga dalam memilih, mengolah dan menyajikan makanan serta meningkatkan kualitas pelayanan kesehatan dan gizi (Sukmawati et al., 2019).

Kehamilan bisa berkembang menjadi masalah dan membawa resiko bagi ibu hamil serta mengancam jiwanya. Sebagian penyebab dapat dicegah melalui pemberian pelayanan kesehatan ibu hamil, dapat diwujudkan melalui pemberian pelayanan antenatal sekurang-kurangnya 4 kali selama masa kehamilan, untuk menjamin perlindungan terhadap ibu hamil dan janin, berupa deteksi dini factor resiko, pencegahan dan penanganan dini komplikasi kehamilan. Salah satu pelayanan antenatal yang dilakukan adalah pelayanan tes laboratorium sederhana, minimal tes kadar hemoglobin ( $\mathrm{Hb}$ ) dan golongan darah (Nur Scholichah, 2018). Untuk mendeteksi dini anemia yang dialami oleh ibu hamil maka dilakukan pemeriksaan kadar hemoglobin dengan metode yaitu cyanmethehemoglobin langsung di laboratorium atau dengan fotometer hemoglobin portable.

Pemeriksaan ini biasanya dilakukan pertama sebelum minggu ke 12 dalam kehamilan dan minggu ke 28. Jika ibu hamil tidak melakukan pemeriksaan hemoglobin selama kehamilannya akan meningkatkan resiko terjadinya anemia yang lebih berat, perdarahan saat persalinan yang tidak terduga yang bisa menjadi penyebab kematian ibu dan janin (Who, 2018). Dampak yang terjadi pada ibu hamil yang mengalamai anemia dapat mengakibatkan terjadinya abortus, persalinan pre maturitas, hambatan tubuh kembang janin dalam rahim, mudah terjadi infeksi, perdarahan antepartum, ketuban pecah dini (KPD) saat persalinan dapat mengakibatkan gangguan His, kala pertama dapat berlangsung lama, terjadi partus terlantar, pada 
Volume: 1 | Nomor 1 | Januari 2022 | E-ISSN: xxxx-Xxxx |

DOI: doi.org/healthcaring.v1n1.1319

kala nifas terjadi subinvolusi uteri menimbulkan perdarahan postpartum dan memudahkan infeksi puerperium dan pengeluaran ASI berkurang (Desty, 2019).

Upaya penanganan yang dilakukan oleh pemerintah untuk menanggulangi masalah anemia yang diakibatkan defisiensi zat besi pada ibu hamil, yakni dengan cara pemberian tablet Fe (tambah darah) dimana, tablet Fe tersebut harus dikonsumsi setiap hari minimal selama 90 hari dalam masa kehamilan (kemenkes, 2018). Menurut data World Health Organization (WHO), angka kematian ibu di dunia pada tahun 2015 adalah 216 per 100.000 kelahiran hidup atau diperkirakan jumlah kematian ibu adalah 810.000 kematian dengan jumlah tertinggi berada di negara berkembang yaitu 302.000 kematian ibu. Berdasarkan hasil Survei Penduduk Antar Sensus (SUPAS) 2015 AKI di Indonesia 305 kematian ibu per 100.000 kelahiran hidup (Profil Kesehatan Indonesia, 2019) .Jumlah Kematian ibu di Sumatera Utara tahun 2019 sebanyak 59,16 dari 100.000 kelahiran hidup (Kemenkes, 2020). Angka Kematian Ibu (AKI) dapat diakibatkan oleh komplikasi saat kehamilan dan setelah persalinan. Komplikasi utama yang menyebabkan hampir 75\% dari semua kematian ibu salah satunya adalah perdarahan hebat (Susiana, 2019). Perdarahan erat kaitannya dengan anemia pada ibu hamil karena ibu hamil yang mengalami perdarahan dapat diakibatkan oleh anemia, Hb yang <11 mg/dl mengakibatkan kurangnya oksigen yang dibawa ke sel tubuh maupun otak dan uterus (Nurun, 2019).

Secara global tahun 2016, 40\% masalah anemia terjadi pada wanita hamil, dan Negara bagian Asia Tenggara memilik prevelensi tertinggi anemia di Myanmar dengan angka kejadian 53,48\% (WHO, 2016). Hasil Riset Kesehatan Dasar (2018) menyebutkan terdapat kejadian anemia pada ibu hamil di Indonesia sebesar 48,9\% yang mengalami kenaikan dari tahun 2013 yaitu 37,1\% (Riskesdas, 2019). Menurut Dinas kesehatan Sumatera Utara tahun (2017) menggambarkan Prevelensi kejadian anemia pada kehamilan di Provinsi Sumatera Utara tahun 2017 sebesar 15\% - 39\% (Dinkes Sumut, 2018). Laporan Dinas Kesehatan Kota Medan (2018) menunjukkan data dari 39.240 ibu hamil terdapat 780 ibu hamil yang mengalami anemia. Kejadian tertinggi terjadi di kabupaten Serdang Bedagai memiliki angka anemia yang cukup tinggi bila dibandingkan dengan kabupaten lain yaitu 37,6\%. (Dinkes Kab.Serdang Bedagai, 2018).

Hasil penelitian Irna Diyana Kartika dkk (2020) mengatakan bahwa dari 50 responden ibu hamil yang berumur kehamilan trimester II dan III maka didapatkan sebanyak 43 orang ibu hamil pada trimester III mengalami anemia dan sisanya 5 orang trimester II yang mengalami anemia dan 2 orang trimester III tidak mengalami anemia (Irna Diyana, 2020).

Hasil penelitian Nur Sholichah dkk (2018) tentang gambaran pemeriksaan HB pada ibu hamil di wilayah kerja puskesmas Banyuasin kecamatan Loano Kabupaten Purworejo menggambarkan bahwa factor yang mempengaruhi kejadian anemia yaitu karena adanya umur, pendidikan dan pengetahuan dalam pemeriksaan hb. Dimana dari 85 responden diketahui umur 20-35 tahun ada 60 responden yang beresiko anemia dan umur $<20$ tahun ada 11 responden $(12,9 \%)$ yang tidak beresiko anemia. Kemudian dari 85 responden dilihat dari pendidikan ada 48 responden (50,3\%) yang berpendidikan SMP berpeluang mengalami anemia dibandingkan dengan 4 responden yang berpendidikan tinggi yang tidak beresiko anemia. Kemudian dari 85 responden ada 39 responden $(45,9 \%)$ yang tidak melakukan pemeriksaan hemoglobin, yang melakukan pemeriksaan 1 kali sebanyak 42 responden (49,4\%), dibandingkan dengan 4 responden (4,7\%) yang melakukan pemeriksaan hb sebanyak 2 kali (Nur Scholichah, 2018).

Berdasarkan hasil penelitian Nurul Ayati Khasanah (2019) usia responden bahwa sebagian besar responden (82,5\%) memiliki usia 20-35 tahun yaitu 56,7\% kelompok kasus dan 91,1\% termasuk kelompok kontrol. Paritas responden, sebagian besar $(71,7 \%)$ memiliki paritas multigravida yang terdiri dari 83,3\% kelompok kasus dan 67,8\% kelompok kontrol. Responden 65,8\% berpendidikan terakhir SMU dan Perguruan tinggi dengan sebagian besar 73,3\% tidak anemia dan 43,3\% anemia. Lebih dari 


\section{Health Caring: Jurnal Ilmiah Kesehatan}

Volume: 1 | Nomor 1 | Januari 2022 | E-ISSN: xxxx-Xxxx |

DOI: doi.org/healthcaring.v1n1.1319

setengah responden $(56,7 \%)$ memilik pekerjaan produktif selain menjadi ibu rumah tangga yaitu $30 \%$ ibu anemia dan 65,6\% tidak anemia (Nurul, 2019).

Diikuti dengan prevelensi anemia pada ibu hamil di puskesmas Sialang Buah yang mengalami peningkatan dimana pada tahun 2018 mengalami peningkatan sebesar 40,7\% (Profil Puskesmas Sialang Buah, 2018). Maka dari itu solusi yang dapat dilakukan dalam upaya skrining safe Motherhood pada kehamilan yaitu pelayanan antenatal, yang bertujuan untuk memantau perkembangan kehamilan secara dini dan penatalaksanaan secara benar sehingga semua kelainan dalam pemeriksaan dapat ditangani secara dini. Deteksi dini perdarahan dan infeksi dapat dilakukan dengan cara skrinning ibu hamil yang menderita anemia yaitu pengecekan hemoglobin selama kehamilan (Chusnul Chotimah, 2018).

Diperlukan adanya sosialisasi untuk peningkatan pengetahuan dan pemahaman masyarakat tentang anemia pada ibu hamil agar kesadaran tentang bahaya anemia pada ibu hamil dapat menjadi motivasi dalam melakukan skrining atau deteksi dini terjadi nya anemia dengan melakukan pemeriksaan kadar hemoglobin dan meningkatkan upaya untuk pencegahan dan penanganan anemia pada ibu hamil di masyarakat. Upaya pemberdayaan masyarakat merupakan salah satu upaya yang dapat digunakan sebagai strategi promosi kesehatan baik level primer maupun tersier sesuai dengan piagam Ottawa carter (Kemenkes, 2017 ).Sebagian besar anemia di Indonesia selama ini dinyatakan sebagai akibat kekurangan besi $(\mathrm{Fe})$ yang diperlukan untuk pembentukan hemoglobin, sehingga pemerintah Indonesia mengatasinya dengan mengadakan pemberian suplemen besi untuk ibu hamil, namun hasilnya belum memuaskan. Penduduk Indonesia pada umumnya mengkonsumsi Fe dari sumber nabati yang memiliki daya serap rendah dibanding sumber hewani. Kebutuhan Fe pada janin akan meningkat hingga pada trimester akhir sehingga diperlukan suplemen Fe (Ari et al., 2018).

\section{Metode Penelitian}

Jenis penelitian adalah deskriptif yang dilakukan di Klinik Helen Tarigan. Populasi semua ibu hamil yang berkunjung di Klinik Helen Tarigan, sampel berjumlah 20 responden. Teknik pengambilan sampel adalah total sampling. Pengumpulan data menggunakan data primer dengan kuesioner. Analisa data dengan menggunakan analisa univariat untuk distribusi frekuensi.

\section{Hasil}

Tabel 1 Distribusi Frekuensi Responden Pengetahuan tanda dan gejala tentang deteksi dini anemia pada ibu hamil di klinik Helen Tarigan tahun 2021

\begin{tabular}{lcc}
\hline \multicolumn{1}{c}{ Pengetahuan } & Frekuensi & $\%$ \\
Baik & 5 & 25.0 \\
Cukup & 10 & 50.0 \\
Kurang & 5 & 25.0 \\
Jumlah & 20 & 100
\end{tabular}

Sumber: Data Primer (2021)

Berdasarkan tabel 1 diatas di peroleh data bahwa mayoritas berpengetahuan cukup sebanyak 10 responden (50\%), baik sebanyak 5 (25\%) dan kurang sebanyak $5(25 \%)$. 


\section{Health Caring: Jurnal Ilmiah Kesehatan}

Volume: 1 | Nomor 1 | Januari 2022 | E-ISSN: xxxx-Xxxx |

DOI: doi.org/healthcaring.v1n1.1319

Tabel 2 Distribusi Frekuensi Responden Pengetahuan meliputi usia

\begin{tabular}{lcc}
\hline \multicolumn{1}{c}{ Pengetahuan } & Frekuensi & $\%$ \\
20-35 tahun & 18 & 90. \\
$>35$ tahun & 2 & 10.0 \\
Jumlah & 20 & 100
\end{tabular}

Sumber: Data Primer (2021)

Berdasarkan tabel 2 diatas di peroleh data bahwa sebagian besar berusia 20-35 tahun sebanyak 18 orang $(90 \%)$ dan sebagian kecil rentang usia responden $>35$ tahun 2 orang $(10 \%)$.

Tabel 3 Distribusi Frekuensi Responden pengetahuan meliputi pendidikan

\begin{tabular}{lcc}
\hline \multicolumn{1}{c}{ Pengetahuan } & Frekuensi & $\%$ \\
SD & 2 & 10.0 \\
SMP & 4 & 20 \\
SMA & 14 & 70.0 \\
Jumlah & 20 & 100
\end{tabular}

Sumber: Data Primer (2021)

Berdasarkan tabel 3 diatas di peroleh data bahwa mayoritas responden yang berpendidikan SMA sederajat sebanyak 14 orang (70\%) dan minoritas yang berpendidikan SD sebanyak 2 orang (10\%).

Tabel 4 Distribusi Frekuensi Responden Pengetahuan meliputi pekerjaan

\begin{tabular}{lcc}
\hline \multicolumn{1}{c}{ Pengetahuan } & Frekuensi & $\%$ \\
Bekerja & 5 & 25.0 \\
Tidak bekerja & 15 & 75.0 \\
Jumlah & 20 & 100
\end{tabular}

Sumber: Data Primer (2021)

Berdasarkan tabel 4 diatas di peroleh data bahwa mayoritas tidak bekerja sebanyak 15 orang (75\%) dan minoritas yang bekerja sebanyak 5 orang $(25 \%)$.

Tabel 5 Distribusi Frekuensi Responden Pengetahuan meliputi paritas

\begin{tabular}{lcc}
\hline \multicolumn{1}{c}{ Pengetahuan } & Frekuensi & \% \\
primigravida & 9 & 45.0 \\
multigravida & 11 & 55.0 \\
Jumlah & 20 & 100
\end{tabular}


Volume: 1 | Nomor 1 | Januari 2022 | E-ISSN: xxxx-xxxx |

DOI: doi.org/healthcaring.v1n1.1319

Sumber: Data Primer (2021)

Berdasarkan tabel 5 diatas di peroleh data bahwa paling besar paritas Multigravida sebanyak 11 orang (45\%) dan paling kecil paritas primigravida 9 orang (45\%).

\section{Tabel 6 Distribusi Frekuensi Responden Kadar hb pada ibu hamil di Klinik Helen Tarigan}

\begin{tabular}{lcc}
\hline \multicolumn{1}{c}{ Pengetahuan } & Frekuensi & \% \\
Tidak anemia & 7 & 35.0 \\
Anemia Ringan & 9 & 45.0 \\
Anemia Sedang & 3 & 15.0 \\
Anemia Berat & 1 & 5.0 \\
Jumlah & 20 & 100
\end{tabular}

Sumber: Data Primer (2021)

Berdasarkan tabel 6 diatas di peroleh data bahwa paling banyak anemia ringan sebanyak 9 orang (45\%), tidak anemia sebanyak 7 orang (35\%), anemia sedang sebanyak 3 orang (15\%) sedangkan paling sedikit anemia berat sebanyak 1 orang $(5 \%)$.

\section{Pembahasan}

\section{Pengetahuan Tanda dan Gejala Tentang Deteksi Dini Anemia}

Bedasarkan hasil penelitian yang dilakukan menunjukkan bahwa tingkat pengetahuan tanda dan gejala pada ibu hamil tentang deteksi dini anemia untuk keseluruhan dalam kategori cukup yaitu sebanyak 10 (50.0\%). Dalam penelitian ini alasan responden karena kurang nya informasi dan edukasi tentang deteksi dini anemia dari tenaga kesehatan.

Secara umum dapat diketahui bahwa pengetahuan seseorang terhadap sesuatu hal dimulai dengan melakukan pengindraan terhadap suatu obyek tertentu. Sebagian besar pengetahuan manusia diperoleh melalui mata dan telinga, setelah itu akan diikuti dengan rasa ketertarikan, kemudian berusaha beradaptasi dengan apa yang di ketahui, pengetahuan secara langsung maupun tidak langsung akan berpengaruh pada perilaku seseorang (Notoatmodjo, 2017).

Sejalan dengan penelitian Annisa Fitri (2018) yang berjudul “ kemampuan deteksi dini anemia pada ibu hamil di kota semarang tahun 2018 yaitu dari 76 responden ada sebanyak 61 responden $(80,3 \%)$ berpengetahuan cukup hal ini disebabkan karena responden tidak mendapatkan informasi tentang tanda dan gejala anemia yang dialami saat kehamilan, selain itu kejadian anemia belum bisa dipastikan tanpa dilakukan pemeriksaan kadar hb.

Akan tetapi hasil penelitian ini tidak sejalan yang dilakukan oleh Siantarini, dkk (2018) yang berjudul Tingkat pengetahuan tentang deteksi anemia dengan perilaku pemenuhan kebutuhan zat besi pada ibu hamil tahun 2018 menyebutkan berpengetahuan baik. Hal ini disebabkan karena responden sudah memiliki informasi terkait deteksi anemia dalam kehamilan diantaranya pengertian, penyebab dan gejala klinis, efek anemia dan sumber-sumber makanan yang mengandung zat besi. Selain itu, informasi terkait deteksi anemia dalam kehamilan diperoleh dari petugas puskesmas setelah menjalani pemeriksaan $\mathrm{Hb}$, dari media seperti majalah dan internet dan seminar kesehatan yang pernah diikuti. 


\section{Health Caring: Jurnal Ilmiah Kesehatan}

Volume: 1 | Nomor 1 | Januari 2022 | E-ISSN: xxxx-Xxxx |

DOI: doi.org/healthcaring.v1n1.1319

Peneliti berasumsi ini terjadi karena karena kurangnya sumber informasi yang diperoleh repsonden dimana semakin banyak informasi yang kita peroleh maka pengetahuan dan wawasan juga akan luas. Sebaliknya bila ibu memiliki sumber informasi yang rendah akan memperoleh pengetahuan yang rendah pula. Tetapi sebagian besar pengetahuan ibu karena factor usia, pendidikan, pengalaman sendiri maupun pengalaman orang lain, media masa maupun lingkungan.

\section{Pengetahuan meliputi usia}

Berdasarkan karakteristik meliputi usia tentang deteksi dini anemia pada ibu hamil di Klinik Helen Tarigan Tahun 2021 oleh peneliti dengan jumlah responden sebanyak 20 orang bahwa sebagian besar berusia 20-35 tahun sebanyak 18 orang (90\%) dan sebagian kecil rentang usia reponden $>35$ tahun sebanyak 2 orang $(10 \%)$.

Umur adalah usia yang terhitung mulai saat dilahirkan sampai saat ia akan berulang tahun. Semakin cukup umur, tingkat kematangan dan kekuatan seseorang akan lebih matang dalam berpikir dan bekerja. Dari segi kepercayaan masyarakat yang lebih dewasa akan lebih percaya dari pada orang yang belum cukup tinggi tingkat kedewasaannya. Hal ini sebagai akibat dari pengalaman dan kematangan jiwanya.

Menurut manuaba (2007) bahwa usia merupakan bagian dari status kesehatan reproduksi terpenting. Usia berkaitan dengan peningkatan atau penurunan fungsi tubuh sehingga mempengaruhi status kesehatan seseorang. Pada usia 20-35 tahun atau lebih akan terjadi perubahan pada jaringan dan alat reproduksi.

Sejalan dengan penelitian Nor Tri dengan judul Tingkat pengetahuan ibu hamil tentang anemia di RS.Panti Wilasa Citarum Semarang yaitu usia 20-35 tahun sebanyak 29 orang (85,3\%) hal ini di sebabkan karena kurang nya pemahaman tentang deteksi dini anemia dan kurang nya informasi yang didapatkan dari tenaga kesehatan.

Akan tetapi penelitian ini bertolak belakang dengan penelitian Rochany, dkk (2020) dengan judul gambaran tingkat pengetahuan tentang anemia dan kepatuhan minum tablet fe pada ibu hamil dengan anemia di Wilayah Kerja Puskesma Cilacap Tengah 1 menyebutkan mayoritas usia $>35$ tahun. Hal ini disebabkan karena ibu yang usia lebih dari 35 tahun cenderung kurang peduli terhadap kehamilannya.

Peneliti berasumsi bahwa usia 20-30 tahun berpengetahuan cukup. disebabkan karena ibu masih dalam usia produktif sehingga ibu masih dapat menerima informasi yang diberikan dari orang lain serta tenaga kesehatan dan rasa ingin tau ibu dalam menggali pengetahuan dan informasi juga lebih tinggi.

\section{Pengetahuan meliputi pendidikan}

Berdasarkan hasil penelitian, bahwa Gambaran pendidikan ibu hamil tentang deteksi dini anemia pada ibu hamil di Klinik Helen Tarigan Tahun 2021 oleh peneliti dengan jumlah responden sebanyak 20 orang mayoritas yang mempunyai pendidikan SMA sebanyak 14 orang (70\%), SMP sebanyak 4 orang (20\%) dan SD sebanyak 2 orang (10\%).

Pendidikan mempengaruhi proses belajar, makin tinggi pendidikan seseorang akan cenderung untuk mendapatkan informasi, baik dari orang lain maupun media masa. Semakin banyak informasi yang masuk semakin banyak pula pengetahuan yang didapat. Tingkat pendidikan seseorang akan berpengaruh dalam memberi respon terhadap sesuatu yang datang dari luar. Tingkat pendidikan mempunyai hubungan yang bermakna dengan pengetahuan ibu hamil mengenai deteksi dini dalam kehamilan. Ibu hamil yang berpendidikan tinggi mempunyai pegetahuan lebih baik mengenai deteksi dini dalam kehamilan dibandingkan dengan ibu hamil yang berpendidikan rendah (Haryati N., 2014). 


\section{Health Caring: Jurnal Ilmiah Kesehatan}

Volume: 1 | Nomor 1 | Januari 2022 | E-ISSN: xxxx-Xxxx |

DOI: doi.org/healthcaring.v1n1.1319

Menurut Notoatmodjo (2017), sikap dan tindakan seseorang yang didasari oleh pendidikan akan langgeng. Tingkat pendidikan ibu akan menentukan sikap dan tindakannya dalam menghadapi berbagai masalah khususnya masalah kesehatan. Ibu yang berpendidikan tinggi semakin mudah menyerap informasi sehingga memiliki persepsi yang lebih baik dibandingkan dengan yang berpendidikan menengah atau dasar (Notoatmodjo, 2017).

Sejalan dengan penelitian Anisa Fitri (2018) yang berjudul Studi deskriptif kemampuan deteksi dini anemia pada ibu hamil di kota Semarang mayoritas berpendidikan SMA. Hal ini disebabkan responden tidak mendapatkan informasi tentang tanda dan gejala anemia yang dialami saat kehamilan, selain itu kejadian anemia belum bisa dipastikan tanpa pemeriksaan darah.

Akan tetapi penelitian ini tidak sejalan dengan penelitian Mahdalena, dkk (2016) dengan judul tingkat pengetahuan ibu hamil tentang deteksi anemia dengan keteraturan ibu hamil dalam mengkonsumsi tablet Fe di wilayah kerja puskesmas sungai ilmu Kabupaten Padang Pariaman menyebutkan sebagian besar berpendidikan SMP. Hal ini disebabkan karena responden kurang memahami tentang deteksi anemia dan kurangnya kesadaran dalam mencegah terjadinya anemia.

Peneliti berasumsi bahwa pendidikan sangat mempengaruhi tingkat pengetahuan seseorang. Dengan semakin tinggi pendidikan akan semakin mudah untuk menerima informasi dari ide-ide orang lain dan sebaliknya bila ibu yang memiliki latar belakang pendidikan rendah pada umumnya mengalami kesulitan untuk menerima informasi. Hal ini disebebkan karena pendidikan tertinggi yang didapat pada responden adalah pendidikan SMA sehingga ibu mudah dalam menerima informasi. Namun perlu ditekankan bahwa seseorang berpendidikan rendah tidak berarti pengetahuan rendah pula. Peningkatan pengetahuan tidak mutlak diperoleh pada pendidikan nonformal.

\section{Pengetahuan meliputi pekerjaan}

Berdasarkan penelitian ini pengetahuan meliputi pekerjaan tentang deteksi dini anemia pada ibu hamil di Klinik Helen Tarigan Tahun 2021 oleh peneliti dengan jumlah responden sebanyak 20 orang mayoritas pekerjaan Ibu yang tidak bekerja sebanyak 15 orang (75\%) dan minoritas ibu yang bekerja sebanyak 5 orang $(25 \%)$.

Menurut teori yang dikemukakan oleh Notoatmojo, pekerjaan adalah suatu yang dikerjakan untuk mendapatkan nafkah atau pencaharian. Masyarakat yang sibuk dengan kegiatan atau pekerjaan sehari-hari akan memiliki waktu yang sedikit untuk memperoleh informasi. Masyarakat yang sibuk hanya memiliki sedikit waktu untuk memperoleh informasi sehingga pengetahuan yang mereka peroleh kemungkinan juga berkurang.

Menurut Thomas yang dikutip Nursalam (2003), pekerjaan adalah keburukan yang harus dilakukan terutama untuk menunjang kehidupannya dan kehidupan keluarga. Pekerjaan bukanlah sumber kesenangan, tetapi lebih banyak merupakan cara mencari nafkah yang membosankan, berulang dan banyak tantangan. Sedangkan bekerja umumnya merupakan kegiatan yang menyita waktu. Bekerja pada ibu-ibu akan mempunyai pengaruh terhadap kehidupan keluarga.

Sejalan dengan penelitian Yuni yang berjudul Gambaran karakteristik anemia pada ibu hamil di Puskesmas Sanden Bantul Yogyakarta mayoritas pekerjaan ibu rumah tangga sebanyak 39 orang (61\%). Hal ini disebabkan karena ibu hamil yang tidak bekerja menimbulkan berbagai factor yang mempengaruhi, misalnya ibu yang terlalu sibuk dengan menyelesaikan tugas rumah dan dalam mengurus suami maupun pendidikan anak sehingga ibu tidak memperhatikan dirinya sendiri dan kurang nya mendapatkan informasi dari tenaga kesehatan. 


\section{Health Caring: Jurnal Ilmiah Kesehatan}

Volume: 1 | Nomor 1 | Januari 2022 | E-ISSN: xxxx-Xxxx |

DOI: doi.org/healthcaring.v1n1.1319

Akan tetapi penelitian ini tidak sejalan dengan penelitian Anfiksyar K, dkk (2019) yang berjudul karakteristik anemia pada kehamilan di poliklinik kebidanan RSUP Sanglah menyebutkan bahwa paling banyak ibu yang bekerja. Hal ini disebabkan karena kesibukan ibu yang membuat ibu kurang peduli dengan kehamilannya dan kurang nya kesempatan ibu dalam menerima informasi.

Peneliti berasumsi bahwa ibu yang tidak bekerja banyak berpengatahuan cukup. Hal ini disebabkan karena ibu tidak memiliki penghasilan maka tingkat ekonomi menjadi rendah sehingga mengakibatkan kemampuan ibu hamil untuk memperoleh informasi dan melakukan pemeriksaan kehamilan menjadi berkurang. Namun disisi lain ibu lebih banyak waktu luang untuk mengikuti berbagai penyuluhan meskipun mempunyai keterbataasan dalam hal keuangan.

\section{Pengetahuan meliputi paritas}

Berdasarkan hasil penelitian ini jumlah kehamilan di Klinik Helen Tarigan Tahun 2021 oleh peneliti dengan jumlah responden sebanyak 20 orang mayoritas multigravida sebanyak 11 orang (55\%) dan minoritas primigravida sebanyak 9 orang $(45 \%)$.

Paritas adalah banyaknya kelahiran hidup yang dipunyai oleh seorang wanita. Paritas dapat dibedakan menjadi primigravida, multigravida dan grandemultigravida. Paritas adalah wanita yang pernah melahirkan bayi aterm. (Marselly,2014). Primigravida adalah ibu yang hamil 1 kali. Multigravida adala seorang ibu yang hamil lebih dari 1 kali. Frekuensi kehamilan atau gravida dan usia kehamilan merupakan suatu karakteristik yang juga termasuk factor pendukung yang dapat memperngaruhi tingkat pengetahuan responden (Notoadmodjo, 2010).

Sejalan dengan penelitian Yuni dengan judul Gambaran karakteristik anemia pada ibu hamil di puskesmas sanden bantul Yogyakarta bahwa mayoritas adalah multi sebanyak 37 orang (57,8\%). Hal ini disebabkan ibu sering tidak memperhatikan dengan kondisi kehamilannya karena beranggapan bahwa sudah berpengalaman pada kehamilan sebelumnya sehingga tidak termotivasi untuk memperhatikan kehamilannya.

Akan tetapi penelitian ini tidak sejalan dengan penelitan Anfiksyar, dkk (2019) yang berujudul karakteristik anemia pada kehamialn di poliklinik kebidanan RSUP Sanglah menyebutkan mayoritas paritas primigravida. Hal ini disebabkan karena responden tidak memperhatikan kehamilannya, kurang mendapatkan informasi dari orang lain dan tidak memiliki pengalaman.

Peneliti berasumsi bahwa ibu berparitas multigravida yang berpengetahuan cukup, hal ini disebabkan karena banyak ibu hamil yang tidak memperhatikan kehamilannya atau ibu yang terlalu apatis dengan informasi-informasi yang penting tentang deteksi dini anemia yang diberikan bidan maupun tenaga kesehatan sehingga ibu kurang mendapat informasi dari tenaga kesehatan maupun orang lain.

\section{Kadar hemoglobin pada ibu hamil di Klinik Helen Tarigan}

Berdasarkan penelitian yang dilakukan pada observasi kadar sel darah merah di Klinik Helen Tarigan Tahun 2021 oleh peneliti dengan jumlah responden sebanyak 20 orang. Di dapatkan sebanyak mayoritas yang mengalami anemia ringan sebanyak 9 orang (45\%), tidak anemia 7 orang (35\%), anemia sedang sebanyak 3 orang (15\%) dan anemia berat sebanyak 1 orang $(5 \%)$.

Menurut Ikatan Bidan Indonesia (IBI) untuk mendeteksi anemia pada kehamilan maka pemeriksaan kadar $\mathrm{Hb}$ ibu hamil harus dilakukan pada kunjungan pertama dan minggu ke 28. Bila kadar Hb kurang dari 10 gram $\%$ pada kehamilan termasuk anemia dan harus diberikan suplemen tablet besi $(\mathrm{Fe})$, diminum secara 


\section{Health Caring: Jurnal Ilmiah Kesehatan}

Volume: 1 | Nomor 1 | Januari 2022 | E-ISSN: xxxx-Xxxx |

DOI: doi.org/healthcaring.v1n1.1319

teratur 1 tablet per hari selama 90 hari berturut-turut. Bila kadar Hb masih kurang dari 10 gram \% disebut menderita anemia. Anemia dalam kehamilan yang paling sering dijumpai adalah anemia gizi besi, hal ini disebabkan kurangnya asupan gizi dalam makanan karena gangguan resobsi, gangguan penggunaan atau perdarahan. Pemeriksaan kadar hemoglobin yang diajurkan dilakukan pada trismeter pertama dan ketiga kehamilan, sering hanya dapat dilaksanakan pada trimeter kedua kehamilan. Sehingga pemeriksaan $\mathrm{Hb}$ pada kehamilan tidak berjalan dengan seharusnya (Masyudi, 2018).

Haemoglobin $(\mathrm{Hb})$ adalah komponen sel darah merah yang berfungsi menyalurkan oksigen ke seluruh tubuh. Jika $\mathrm{Hb}$ berkurang, jaringan tubuh kekurangan oksigen. Oksigen diperlukan tubuh untuk bahan bakar proses metabolism. Haemoglobin adalah molekul protein pada sel darah merah yang berfungsi sebagai media transport oksigen dari paru-paru. Kandungan zat besi yang terdapat dalam $\mathrm{Hb}$ membuat darah berwarna merah. Pada pemeriksaan dan pengawasan $\mathrm{Hb}$ dapat dilakukan dengan menggunakan metode sachli yang dilakukan minimal 2 kali selama kehamilan yaitu trimester I (umur kehamilan sebelum 12 minggu) dan trimeseter III (umur kehamilan 28 sampai 36 minggu) (Nintyasari, 2017).

Menurut teori deteksi anemia pada kehamilan dilakukan pemeriksaan kadar hb pada ibu hamil. Pengukuran kadar hemoglobin ibu merupakan pemeriksaan sederhana yang dapat dilakukan sebagai parameter yang digunakan secara luas untuk menetapkan prevalensi anemia. Menurut Teori bahwa pada ibu hamil terjadi penurunan kadar $\mathrm{Hb}$ karena penambahan cairan tubuh yang tidak sebanding dengan massa sel darah merah. Penurunan ini terjadi sejak usia kehamilan 8 minggu sampai 32 minggu sehingga ibu hamil itu mengalami anemia (Aldina, dkk 2018).

Penelitian ini sejalan dengan hasil penelitian Luthfi Sasmita (2016) dengan judul gambaran kejadian anemia pada ibu hamil di puskesmas pakualaman kota Yogyakarta tahun 2016 didapatkan bahwa ibu hamil mayoritas mengalami anemia ringan sebanyak 30 orang $(65,2 \%)$ menurut asumsi bahwa disebabkan karena pola makan ibu yang tidak benar dan tata cara meminum tablet Fe yang salah dan kurang mendapatkan informasi mengenai pemeriksaan hb dari tenaga kesehatan.

Akan tetapi penelitian ini bertolak belakang dengan penelitian Anfiksyar, dkk (2019) yang berjudul karakteritik anema pada kehamilan di poliklinik kebidanan RSUP Sanglah menyebutkan mayoritas konsentrasi hb responden yaitu anemia sedang. Hal ini disebabkan karena kurangnya kewaspadaan ibu terhadap kehamilannya dan kurang nya kepedulian ibu untuk mendapatkan informasi serta pemahaman dalam mencegah anemia.

Peneliti berasumsi dari pemeriksaan hemoglobin bahwa ternyata masih banyak ibu hamil yang mengalami anemia ringan. Hal ini dikarenakan ibu hamil tidak rutin dalam mengkonsumsi vitamin penambah darah yang diberikan bidan atau dokter dan kurangnya pemahaman ibu hamil mengenai pemeriksaan hb dan pencegahan anemia ditambah lagi kurangnya edukasi dari tenaga kesehatan kepada para ibu hamil yang menyebabkan ibu hamil tidak mendapatkan pengetahuan mengenai manfaat dan keuntungan pemeriksaan hemoglobin untuk mengetahui status atau nilai kadar hemoglobin mereka.

\section{Kesimpulan}

Berdasarkan hasil penelitian dengan jumlah 20 responden mengenai deteksi dini anemia pada ibu hamil di Klinik Helen Tarigan Tahun 2021 maka dapat disimpulkan:

1. Berdasarkan hasil penelitian berdasarkan pengetahuan ibu hamil mayoritas berpengetahuan cukup $50 \%$, berpengetahuan baik sebanyak 25\% dan berpengatahuan kurang sebanyak $25 \%$. 


\section{Health Caring: Jurnal Ilmiah Kesehatan}

Volume: 1 | Nomor 1 | Januari 2022 | E-ISSN: xxxx-Xxxx |

DOI: doi.org/healthcaring.v1n1.1319

2. Berdasarkan penelitian ini pengetahuan meliputi umur, sebagian besar 20-35 tahun sebanyak 90\% dan sebagian kecil umur $>35$ tahun sebanyak $10 \%$.

3. Berdasarkan pendidikan, mayoritas pendidikan SMA sebanyak $70 \%$, semakin tingginya pendidikan maka akan semakin luas tingkat pengetahuan seseorang dalam menerima setiap informasi. Banyak masyarakat yang menyepelehkan dengan pendidikan padahal sangat berpengaruh pada diri kita sendiri.

4. Berdasarkan pekerjaan, mayoritas tidak bekerja sebanyak $75 \%$, dari penelitian ini seharusnya ibu yang dirumah bisa berpengetahuan baik, karena akan lebih memiliki waktu yang lebih banyak untuk menerima informasi, bahkan ini lebih besar berpengetahuan cukup, dikarenakan banyak ibu rumah tangga yg sepele dengan informasi yang di berikan bidan setempat.

5. Berdasarkan dari pengalaman ibu hamil, mayoritas paritas multigravida sebanyak 55\%, didapatkan lebih banyak ibu hamil di paritas multigravida, namun masih berpengetahuan cukup, dikarenakan ibu yang kurang memperhatikan kehamilannya atau informasi dari bidan tentang deteksi dini anemia

6. Berdasarkan hasil penelitian tentang pemeriksaan kadar hb didapatkan paling banyak ibu hamil yang mengalami anemia ringan sebanyak $45 \%$ dan paling kecil ibu hamil yang mengalami anemia berat $5 \%$.

\section{Referensi}

Aisyah. (2017). Kejadian Anemia pada Ibu Hamil Ditinjau dari Paritas dan Usia. Jurnal Aisyah : Jurnal Ilmu Kesehatan, 2(2), 123-130. https://doi.org/10.30604/jika.v2i2.57

Aisyah. (2017). Kejadian Anemia pada Ibu Hamil Ditinjau dari Paritas dan Usia. Jurnal Aisyah : Jurnal Ilmu Kesehatan, 2(2), 123-130. https://doi.org/10.30604/jika.v2i2.57

Anfiksyar, K. S. S., Aryana, M. B. D., Surya, I. G. N. H. W., \& Manuaba, I. B. G. F. (2019). Karakteristik Anemia pada Kehamilan di Poliklinik Kebidanan PSUP Sanglah Tahun 2016-2017. Jurnal Medika Udayana, 8(7), 1-7.

Ari, D., Yanti, M., \& Sulistianingsih, A. (2018). Care Area District of Pringsewu. 6, 79-87.

Ayu, P., Cahyaning, K., Subawa, A. A. N., \& Lestari, A. A. W. (2020). Gambaran karakteristik anemia defisiensi besi pada ibu hamil di rsup sanglah tahun 2017. 9(2), 40-45.

Chusnul Chotimah. (2018). Predisposisi Perilaku Ibu Hamil Anemia Yang Mempengaruhi Kepatuhan Antenatal Care dan Mengkonsumsi Tablet Fe. Public Health Perspective Journal, 2(2), 148-154.

Dartiwen dan Yati Nurhayati. (2019). Kehamilan.

Desty, dkk. (2019). gambaran jumlah retikulosit pada ibu hamil dengan anemia. Insan Cendekia volume 7, 8(1), 40-46.

Dinkes Kab.Serdang Bedagai. (2018). Hasil riset kesehatan dasar kementerian Republik Indonesia 2018. Kementrian Kesehatan Republik Indonesia, 138-139.

Dinkes Sumut. (2018). Laporan Provinsi Sumatera Utara.

Fitri, A., \& Machmudah. (2018). Studi Deskriptif Kemampuan Deteksi Dini Anemia Pada Ibu Hamil Di 


\section{Health Caring: Jurnal Ilmiah Kesehatan}

Volume: 1 | Nomor 1 | Januari 2022 | E-ISSN: xxxx-Xxxx |

DOI: doi.org/healthcaring.v1n1.1319

Kota Semarang. Studi Deskriptif Kemampuan Deteksi Dini Anemia Pada Ibu Hamil Di Kota Semarang Descriptive Study of Early Anemia Detection Ability in Pregnant Women In Semarang City, 180-187.

Hasnidar. (2020). Faktor-faktor yang mempengaruhi terjadinya anemia pada ibu hamil di Kelurahan Mancanang Wilayah Kerja UPTD Puskesmas Watampone. 5(1), 34-39.

Irna Diyana, dkk. (2020). Pencegahan dan Tata Laksana Awal Penyakit Anemia pada Ibu Hamil di RSIA St. Khadijah 1 Makassar. Jurnal Pengabdian Kedokteran Indonesia, 1(1), 12-16. https://doi.org/10.33096/jpki.v1i1.100

Kemenkes RI. Profil Kesehatan Indonesia tahun 2018. Jakarta : Kemenkes RI; 2018.

Kemenkes RI. Profil Kesehatan Indonesia tahun 2020. Jakarta : Kemenkes RI; 2020.

Masyudi. (2018). Pemeriksaan Haemoglobin Ibu Hamil di Puskesmas Penanggalan Kota Subulussalam. VI(1), 32-43.

Nintyasari, dkk. (2017). Pemeriksaan Kadar Hemoglobin Dan Urine Pada Ibu Hamil Di Laboratorium Kesehatan Terpadu Unimus. Jurnal Unimus, 1, 525-529. https://jurnal.unimus.ac.id/index.php/psn12012010/article/viewFile/2343/2317

Nur Scholichah, H. L. (2018). Gambaran pemeriksaan Hb pada ibu hamil di wilayah kerja puskesma banyuasin kecamatan Loano kabupaten purworejo. GAMBARAN PEMERIKSAAN HB PADA IBU HAMIL DI WILAYAH KERJA PUSKESMAS BANYUASIN KECAMATAN LOANO KABUPATEN PURWOREJO NUT, 1.

Nurun, dkk. (2019). Keterlibatan Suami dalam Melaksanakan Peran Domestik Ibu Hamil dengan Anemia $\begin{array}{lllll}\text { Kehamilan. } & \text {.. } & \text { Nasional } & \text { INAHCO }\end{array}$ https://publikasi.polije.ac.id/index.php/inahco/article/view/1761

Plora Novita. (2019). Kehamilan.

Profil Kesehatan Indonesia, 2019. (2019). Profil Kesehatan 2019. Profil Kesehatan,2019, 98.

RISKESDAS. (2018). Laporan Riset Kesehatan Dasar Provinsi Sumatera Utara tahun 2018. In Balitbangkes.

Riskesdas. (2019). Hasil Riset Kesehatan Dasar Tahun 2018. Kementrian Kesehatan RI, 53(9), 16891699.

Sarwono. (2018). ILMU KEBIDANAN, Jakarta.

Sukmawati, Mamuroh, L., \& Nurhakim, F. (2019). Pengaruh Edukasi Pencegahan dan Penanganan Anemia Terhadap Pengetahuan dan Sikap Ibu Hamil. Jurnal Keperawatan BSI, VII(1), 42-47.

Susiana, S. (2019). Angka Kematian Ibu: Faktor Penyebab Dan Upaya Penanganannya.

WHO Health Statistics. (2017). Monitoring health for the SDGs. Diunduh 20/08/2017,darihttp://www.who.int/gho/publications/world_health_statistics/2017/en/

World Health Organization. (2018). Status of the health-related SDGs. World Health Statistics, 4-12. https://www.who.int/gho/publications/world_health_statistics/2018/EN_WHS2018_Part2.pdf 


\section{Health Caring: Jurnal Ilmiah Kesehatan}

Volume: 1 | Nomor 1 | Januari 2022 | E-ISSN: xxxx-xxxx |

DOI: doi.org/healthcaring.v1n1.1319

World Health Organization. (2019). Status Of The Health-Related SDGS. SDGS: Monitoring for the SDGS. World Health Statistics, 29-35. https://www.who.int/health-topics/anemia/\#tab=tab_1

Widoyoko, A. P. H., \& Septianto, R. (2020). Pengaruh Anemia terhadap Kematian Maternal. Jurnal Penelitian Perawat Profesional, 2(1), 1-6. https://doi.org/10.37287/jppp.v2i1.36 